\title{
Reelin affects chain-migration and differentiation of neural precursor cells
}

\author{
Simone Massalini a , Serena Pellegatta ${ }^{\text {b,c }}$, Federica Pisati ${ }^{\text {b,c }}$, Gaetano Finocchiaro ${ }^{\text {b,c }}$, \\ Maria Giulia Farace ${ }^{a}$, Silvia Anna Ciafrè ${ }^{a, *}$ \\ a Dept. of Experimental Medicine and Biochemical Sciences, University of Rome "Tor Vergata", 00133 Rome, Italy \\ ${ }^{b}$ Dept. of Molecular Neuro-Oncology, Fondazione IRCCS Istituto Neurologico C. Besta, 20133 Milan, Italy \\ c Dept. of Experimental Oncology, IFOM-IEO Campus, European Institute of Oncology, 20139 Milan, Italy
}

\section{A R T I C L E I N F O}

\section{Article history:}

Received 27 May 2009

Revised 4 August 2009

Accepted 10 August 2009

Available online 19 August 2009

\section{Keywords:}

Reelin

Chain-migration

Neural stem cells

Gliom

\begin{abstract}
A B S T R A C T
In the adult mammalian brain, multipotential neural stem cells (NSC) persist throughout life in areas where neurogenesis is maintained. A distinctive trait of NSCs growing in vitro as neurospheres (NS), is their ability to self-renew, differentiate and migrate to sites of injury, such as gliomas. We have studied the role of Reelin, an extracellular matrix protein involved in brain development, in NSCs derived from normal newborn mice or from reeler, a natural mutant in which Reelin is not expressed. We show that the absence of Reelin negatively affects proliferation, NS-forming ability, and neuronal differentiation. Reeler NSCs are unable to migrate in chains, a migration mode typical of neural precursors homing to injury sites in adult CNS. All these effects are partially rescued by ectopic Reelin supplementation. Finally, we show that reeler NSCs fail to migrate in vivo towards gliomas. Overall, our results indicate that Reelin affects all major features of postnatal NSCs, and that it is required for the proper homing of NSCs to tumor sites in adult brain.
\end{abstract}

(C) 2009 Elsevier Inc. All rights reserved.

\section{Introduction}

The mammalian brain was previously considered an organ with very low turn-over and poor regenerative capacity of neuronal cells. However, many lines of evidence have now convincingly demonstrated the existence of adult, multipotential neural stem cells in specific areas of the brain, the same where neurogenesis persists in the adults. These cells respond to the definition of progenitor cells, able to self-renew, differentiate throughout the neuraxis into cells of all glial and neuronal lineages, and capable to re-populate developing or degenerating CNS regions, especially under pathological conditions (Reynolds and Weiss, 1992; Morshead et al., 1994; Doetsch et al., 1999; Johansson et al., 1999; Luskin, 1993; Eriksson et al., 1998; Gage, 2000; Alvarez-Buylla and Garcia-Verdugo, 2002; Taupin and Gage, 2002). Two main sources of adult neural stem cells have been described in the adult brain: the subgranular zone of the hippocampus and the subventricular zone (SVZ) (Doetsch et al 1999; Johansson et al., 1999). Neural stem cells derived from SVZ, the largest population of proliferating cells in the adult rodent brain, gather in "chains," through which they migrate tangentially along the rostral extension of the SVZ into the olfactory bulb (OB), forming the socalled "rostral migratory stream" (RMS) (Lois and Alvarez-Buylla, 1994; Doetsch and Alvarez-Buylla, 1996; Alvarez-Buylla and Garcia-

\footnotetext{
* Corresponding author. Dept. of Experimental Medicine and Biochemical Sciences, University of Rome "Tor Vergata", Via Montpellier, 1, 00133 Roma, Italy. Fax: +39 0672596053.

E-mail address: ciafre@uniroma2.it (S.A. Ciafrè).
}

Verdugo, 2002; Lledo et al., 2006; Wichterle et al., 1997). These cells can be isolated and cultured in vitro as self-adherent cell clusters called neurospheres (Johansson et al., 1999), recapitulating the main biological properties of the original cells.

The recognition that neural stem cells, both mouse and human, can be propagated in culture, re-implanted into mammalian brain, where they can precisely migrate to distant pathological areas and permanently express foreign, therapeutic genes, makes their use quite attractive in the perspective of CNS gene therapy (Flax et al., 1998; Park et al., 2002a,b; Snyder et al., 1997). Specifically, NSCs can respond to homing cues from glioma tumors and disseminated cells, thus reaching and specifically targeting them. (Aboody et al., 2000; Benedetti et al., 2000; Aboody et al., 2008). For further exploitation of these cells in CNS gene and cell therapies, the molecular mechanisms underlying neural stem cell migration through brain matter toward glioma sites need to be understood, together with a deeper elucidation of neural stem cell biology.

Reelin is a large extracellular matrix (ECM) secreted glycoprotein (D'Arcangelo et al., 1995) which binds to very low density lipoprotein receptor (VLDLR), and Apolipoprotein E receptor 2 (ApoER2), triggering the adaptor function of the cytosolic protein disabled-1 (Dab-1) (D'Arcangelo et al., 1999) and the phosphorylation of srcfamily kinases. Reelin expression starts in the developing brain and continues in GABAergic neurons of the cortex and the hippocampus and in glutamatergic granule cells of the cerebellum in adult rodents (Alcantara et al., 1998; Pesold et al., 1998; Ramos-Moreno et al., 2006), non-human primates (Martinez-Cerdeno et al., 2002) and adult humans (Abraham and Meyer, 2003). Besides its well defined 
role in brain development, Reelin was more recently studied in the context of adult mammalian brain, where its function remains quite obscure. It was shown that exogenous Reelin affects the migration of neuronal precursors from explants of postnatal murine subventricular zone (Hack et al., 2002), suggesting a role in adult neurogenesis. In fact, SVZ neurogenesis is impaired in mice lacking reelin (reeler mice), and this affects the initial stages of migration from SVZ via the RMS (Won et al., 2006). Reelin expression was also demonstrated in human neural stem cells, leading to the hypothesis that Reelin transduction signaling pathway might represent an important factor in neural stem cell migration (Kim et al., 2002).

The aim of our study was to investigate the involvement of Reelin in the migratory potential of neural stem cells. We chose postnatal neural stem cells (NSC) isolated from both reeler and wild type mice as our experimental model, and compared their in vitro and in vivo migratory behaviors, specifically focusing on the migration induced by glioblastoma cells or established tumors. The data we collected hint at a new important role for Reelin as a mediator of a specific mode of migration, called "chain migration", a typical property distinguishing this specific category of neural precursors in the injured adult mammalian brain.

\section{Results}

Establishment of postnatal neural stem cells from reeler mice

As in vitro culture of postnatal neural stem cells from the SVZ recapitulates in great part the biological features of these cells in vivo, we took advantage of the natural Reelin knock-out mouse, called reeler, to set up neural stem cell cultures, and compare their properties with those of the wt NSCs derived from wild type littermates. Primary neurospheres were produced from both wild type and reeler neural stem cells in about seven days. By Western blot analysis of the conditioned media of the cultured neurospheres, we confirmed the total absence of Reelin production by reeler NSCs, in contrast with a clearly detectable secretion from wild type cells (Fig. 1A). Under culture conditions favoring the undifferentiated state of NSCs (i.e. in the presence of bFGF and EGF), cells in both reeler and wild type neurospheres showed a strong immunoreactivity to nestin, a stem cell marker, thus validating their stem nature; this was also confirmed by negligible presence of GFAP (an astroglial marker) or $\beta$ tubulin III (a neuronal marker) immunoreactive cells (Fig. 1B). As Reelin is known to play its extracellular role by binding to very low
A

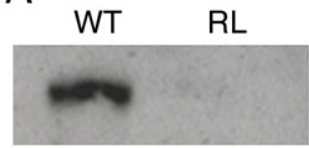

$180 \mathrm{KDa}$

B

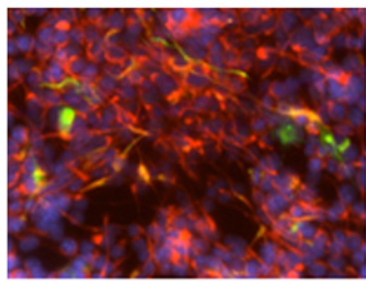

Nestin

GFAP

DAPI

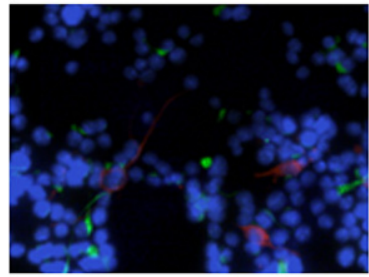

TuJ

GFAP

DAPI

F
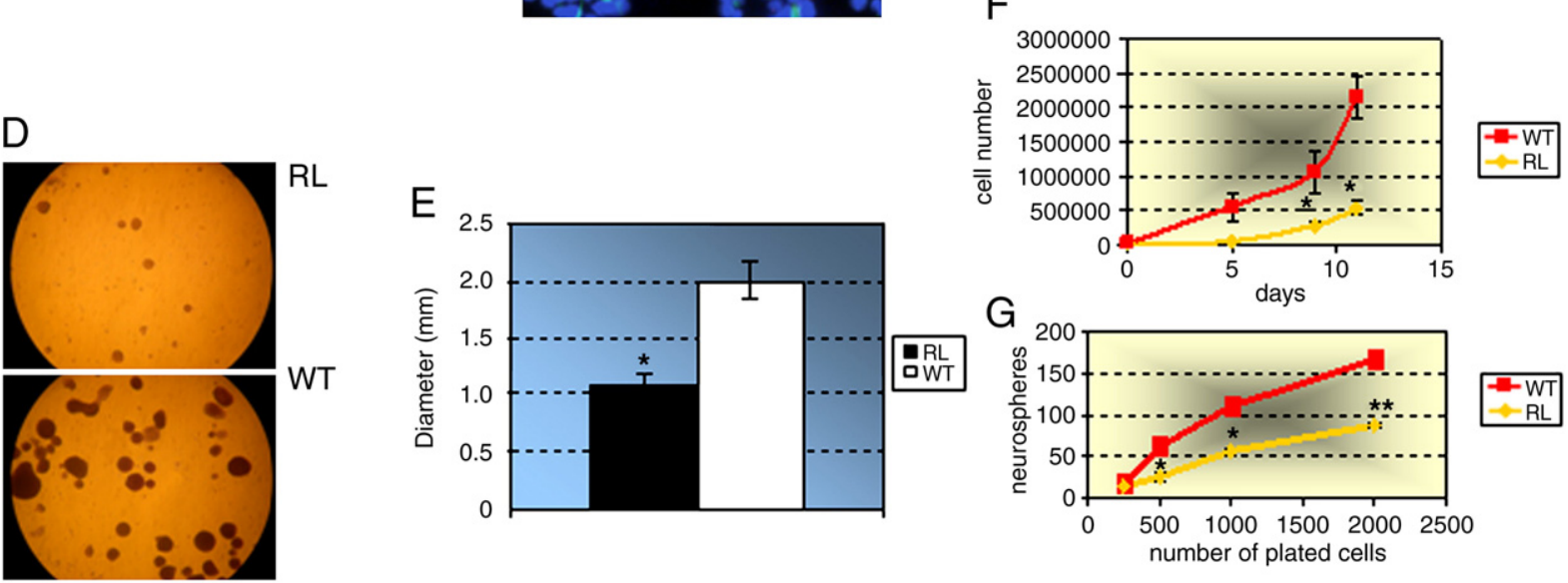

C

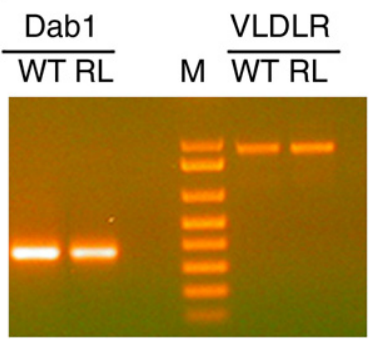

$G$

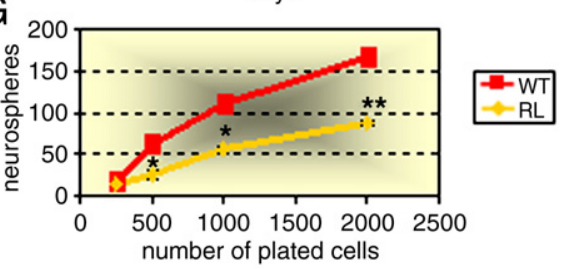

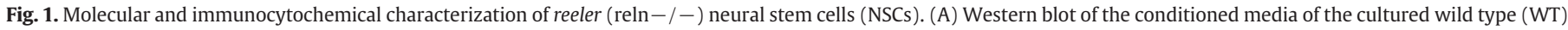

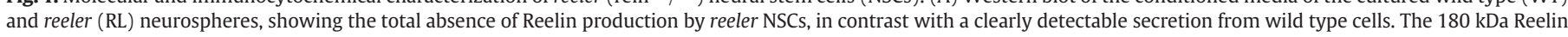

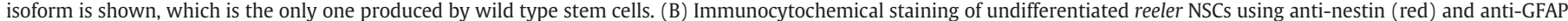

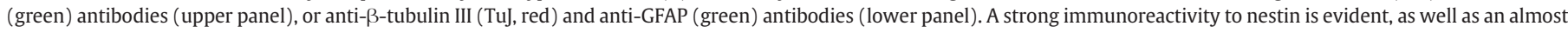

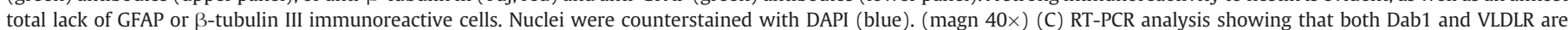

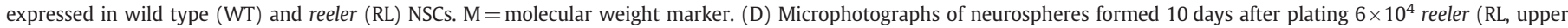

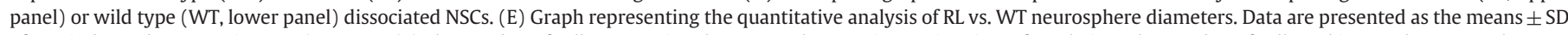

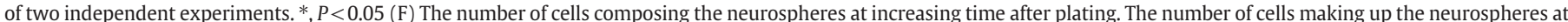

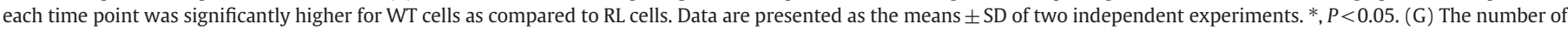

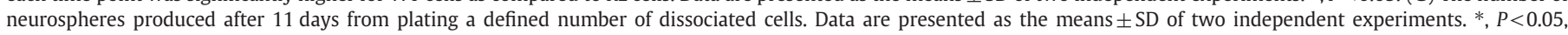
**, $P<0.01$. 

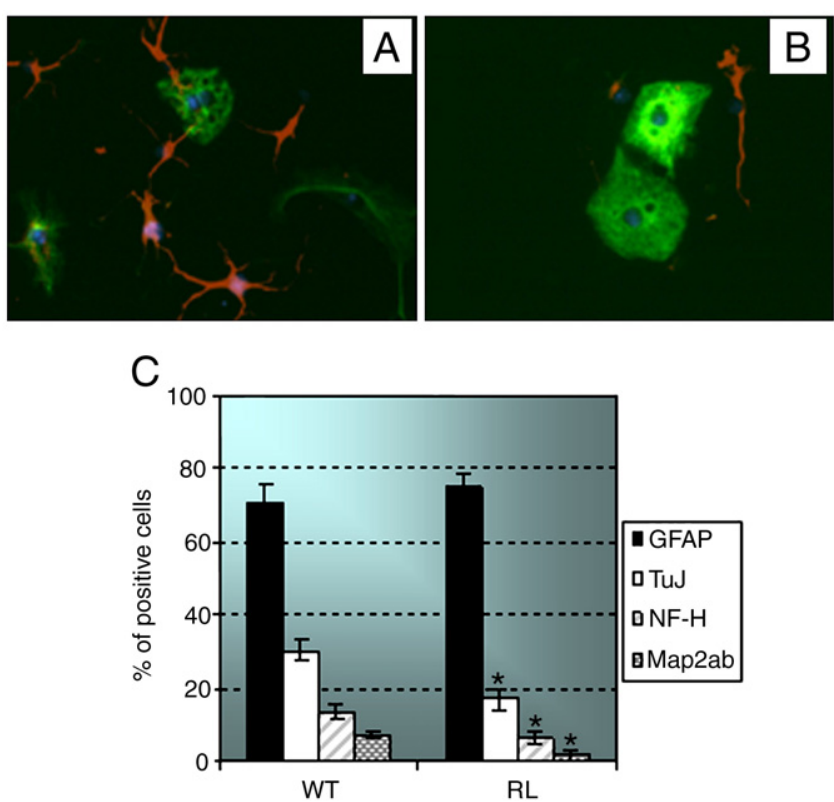

Fig. 2. Lack of Reelin negatively influences neuronal differentiation of NSCs. (A-B) Immunocytochemical staining of differentiated wild type (A) or reeler (B) NSCs using anti-GFAP (green) or anti- $\beta$-tubulin III (red) antibodies. Nuclei were counterstained with DAPI (blue). (C) Bar graph representing the percentage of WT or RL cells expressing the neuronal markers, $\beta$-tubulin III (TuJ), the heavy chain of the neurofilament (NF-H) or Map2, or the astrocytic marker GFAP. Reeler neural stem cells showed a significant reduction in neurons while the number of astrocytes remained unvaried as compared to wild type cells. Data are presented as the means \pm SD of two independent experiments. *, $P<0.05$. density lipoprotein receptor (VLDLR), and then triggering the intracellular adaptor protein Dab1 (D'Arcangelo et al., 1999), we also checked by RT-PCR the expression of the corresponding genes in wild type and reeler NSCs. As shown in Fig. 1C, both genes are expressed in NSCs from both genotypes.

\section{Reelin affects neurosphere and neural stem cell growth}

The first aspect of neural stem cells we studied with regard to Reelin function was their growth ability as single, dissociated cells, and that as neurospheres as a whole. When we plated the same number $\left(6 \times 10^{4}\right)$ of dissociated cells and followed the formation of neurospheres along time, we observed that the diameters of reeler neurospheres were reproducibly smaller than those of wild type ones (wt $2 \mathrm{~mm} \pm 0.3$, reeler $1.2 \mathrm{~mm} \pm 0.2$, after 10 days in culture. *, $P<0.05$ ) (Figs. 1D and E). This result was confirmed by counting the cells composing the neurospheres at increasing time after plating: as shown in Fig. 1F, the number of cells making up the neurospheres at each time point was significantly higher for wild type cells as compared to reeler cells $(*, P<0.05)$. Moreover, when we assayed the "spherogenic" ability (i.e. the number of neurospheres produced after plating a defined number of dissociated cells) of reeler cells, we found that this aspect too was negatively affected by the lack of Reelin production (Fig. 1G. *, $P<0.05$, **, $P<0.01$ ). Thus, these results point toward an involvement of Reelin in growth potential of postnatal neural stem cells, both at the level of single cell proliferative capacity and ability of stem cells to grow and divide inside neurospheres.

\section{Reelin affects neuronal differentiation of neural stem cells}

Neural stem cells can be induced to differentiate by depriving their medium of growth factors. In fact, in the absence of EGF and bFGF, these
A

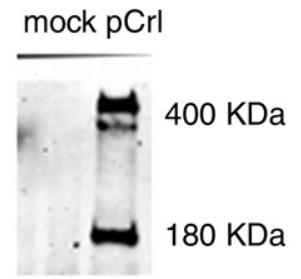

B

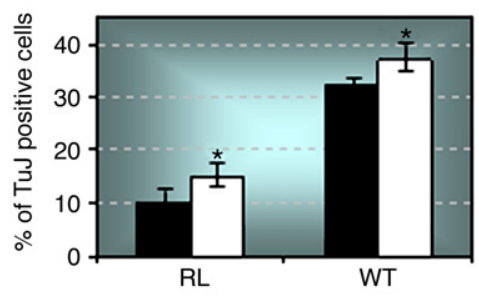

D

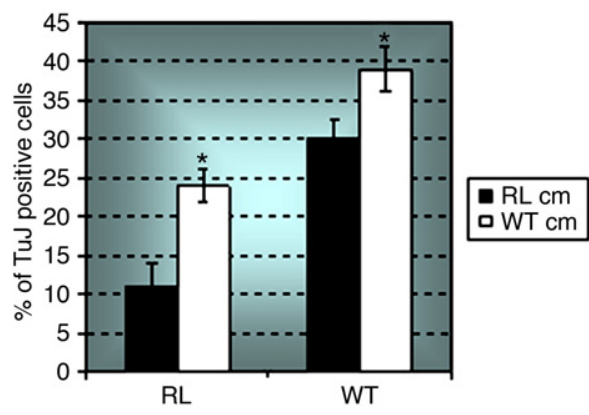

C

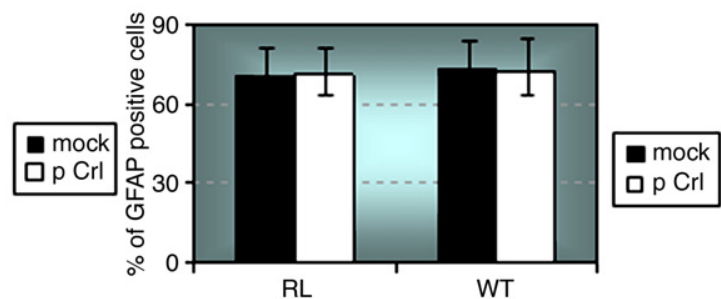

F
E

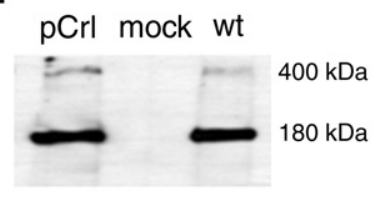

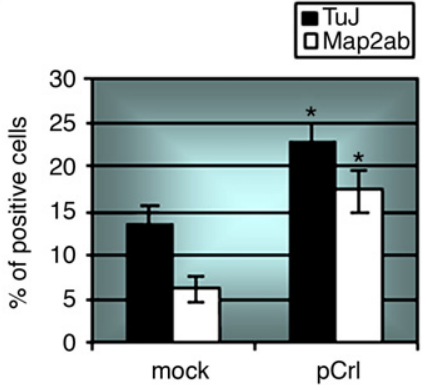

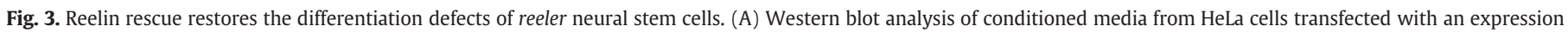

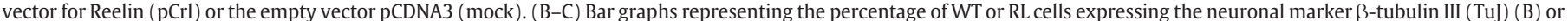

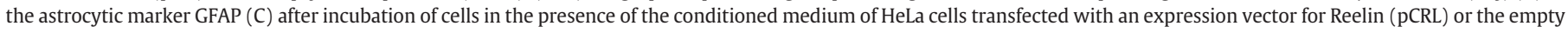

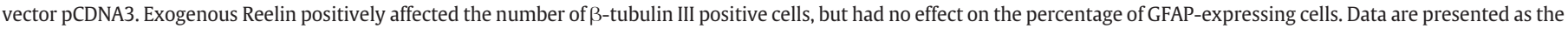

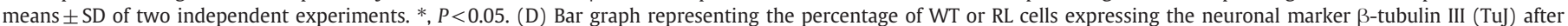

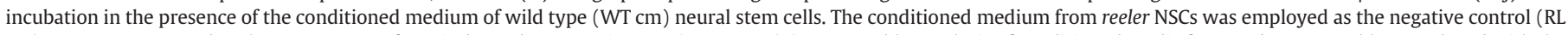

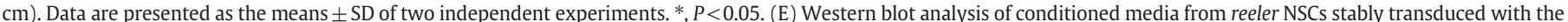

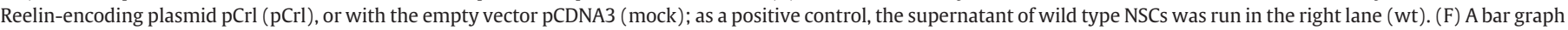

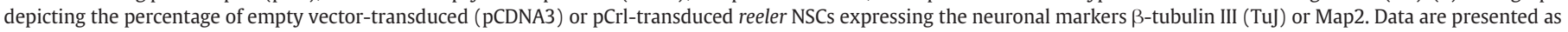
the means \pm SD of two independent experiments. ${ }^{*}, P<0.05$. 
cells exit cell cycle and change their morphology and their gene expression pattern (Doetsch et al., 2002). When put in differentiation conditions, wild type stem cells showed their typical multipotency, generating mainly astrocytes $(70 \% \pm 5 \%)$ and neurons $(30 \% \pm 3 \%)$ (Figs. 2A and C). Moreover, we could recognize several types of neurons, expressing distinct markers, some of which, as $\beta$-tubulin III, are distinctive of early neurogenesis, and others, like the heavy chain of the neurofilament (NF-H) and Map2, depict more mature neurons (Fig. 2C). Reeler neural stem cells, though maintaining the multipotency, showed a significant reduction in neurons ( $\beta$-tubulin III $17 \% \pm 3 \%$ vs. $30 \% \pm 4 \%$; NF-H $6 \% \pm 2 \%$ vs. $12 \% \pm 2$; Map $2 \% \pm 1 \%$ vs. $8 \% \pm 1 \%$. ${ }^{*}$, $P<0.05)$, while the number of astrocytes, measured by GFAP positive staining, remained unvaried as compared to wild type cells (Figs. 2B and C). These data suggest that Reelin affects only neurogenesis but not gliogenesis of murine postnatal neural stem cells.

To prove the direct implication of Reelin on neurogenesis of neural stem cells, we treated reeler and wild type neural stem cells with conditioned medium prepared from HeLa cells transfected with an expression vector for Reelin ( $\mathrm{pCrl}$ ) or the empty vector pcDNA3 (mock) (Fig. 3A). When we added the Reelin-containing medium to differentiating NSCs, we observed an increase $(+5 \%)$ of $\beta$-tubulin III expressing neurons, both in wild type and reeler cells, as compared to the mock medium (Fig. 3B. ${ }^{*}, P<0.05$ ). Again, the number of GFAPexpressing astrocytes remained constant, not being affected by Reelin exogenous supplementation (Fig. 3C). To exclude any unwanted effect due to toxic factors possibly contained in HeLa conditioned medium, we performed the same rescue experiments by using the supernatants of wild type neural stem cells as a source of exogenous Reelin, and reeler cells conditioned medium as the negative control. Fig. 3D shows that neural stem cell-produced Reelin was even more efficient than HeLa-produced Reelin in re-inducing the neurogenic potential of both reeler and wild type cells. In fact, $\beta$-tubulin III positive cells increased by $15 \%$ in reeler cells and by $8 \%$ in wild type cells $(*, P<0.05)$.

As a further step, we tried to restore Reelin expression in reeler neural stem cells by an alternative approach which is the stable
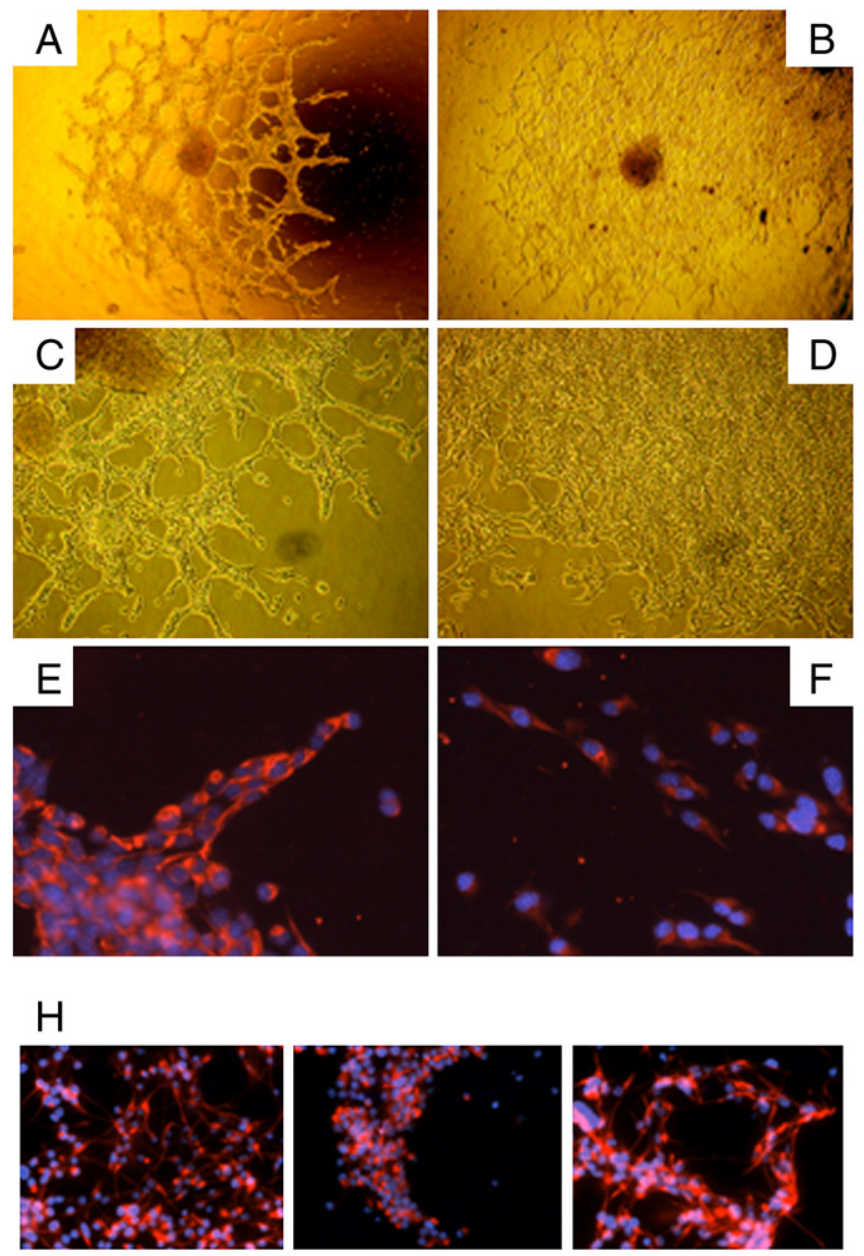

reeler

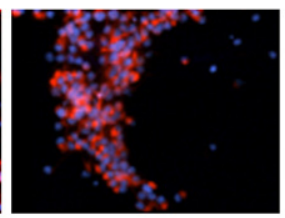

reeler + reelin

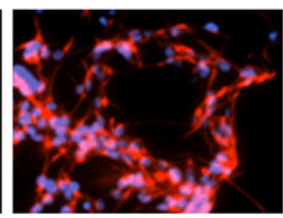

wild type

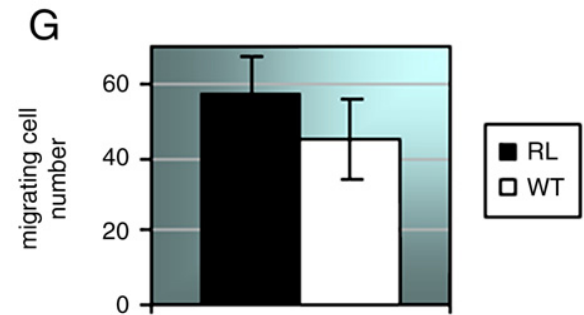

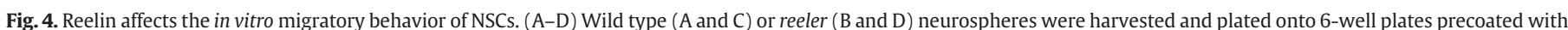

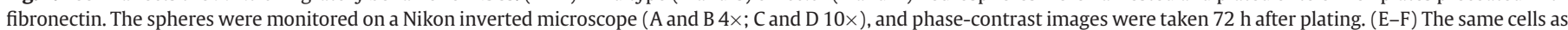

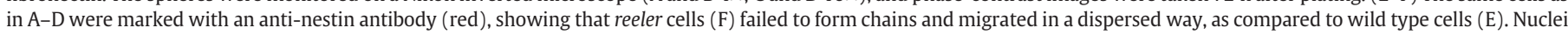

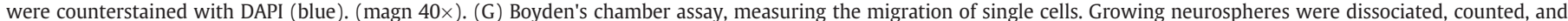

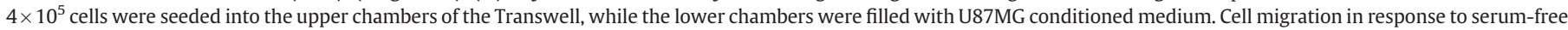

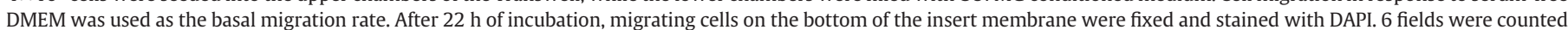

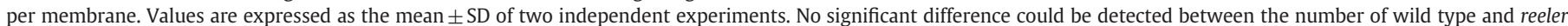

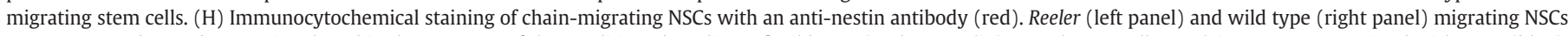

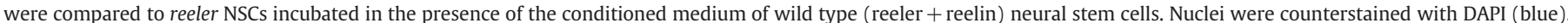

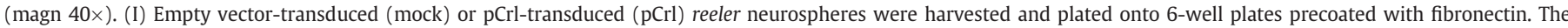

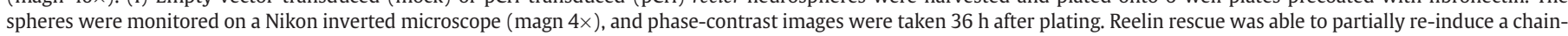
like migratory modality in reeler stem cells. 
transfection with pCrl. Even if stable transduction of neural stem cells is difficult to obtain by traditional methods, we successfully set up a lipofectamine-based protocol allowing us to select stable transfectants actively secreting Reelin at levels comparable to those produced by wild type stem cells (Fig. 3E). As a confirmation of the data previously obtained with exogenously added Reelin, also in this experimental set up Reelin rescue was able to increase the number of $\beta$-tubulin III- and Map2-positive cells generated from reeler stem cells under differentiation conditions (Fig. 3F. ${ }^{*}, P<0.05$ ).

\section{Reeler neural stem cells show an impaired chain migration proficiency}

Another important aspect of neural stem cells, both in normal and in pathological contexts, is their ability to migrate. Specifically, these cells were shown to employ a specialized migratory mode, called "chain migration", characterized by the formation of "cords" of cells sliding along each other toward a physiological or even a pathological cue (Zhao et al., 2008). This mechanism can be reproduced in vitro through neurosphere-based assays, where single neurospheres are allowed to adhere to the surface of a fibronectin-coated culture dish, and cells start migrating outward the neurosphere in a chain-like way. The different behaviors of reeler neural stem cells in this assay as compared to wild type cells are shown in Figs. 4A-D. While cells derived from wild type mice generated chain-like structures that resembled the migratory behavior of stem cells along the rostral migratory stream in vivo (Zhao et al., 2008), neural stem cells that do not express Reelin showed a different pattern of migration, failing to form evident chain structures. The same association pattern is clearly visible in more detail, when the cytoplasms of migrating cellsare marked with an anti-nestin antibody: reeler cells failed to form chains and migrated in a dispersed way (Figs. 4E-F). No staining was obtained for $\beta$-tubulin III (data not shown), allowing to exclude that migrating cells might be differentiating ones. We also checked the general migration ability of reeler stem cells vs. their wild type counterparts, to determine whether Reelin absence is relevant to migration in general or only to chain-like migration. By using a Boyden's chamber assay, where single migrating cells are measured, we demonstrated that no significant difference could be evaluated between the number of wild type and reeler migrating stem cells (Fig. 4G).

Exogenously administered Reelin was tested also in the chain migration assay, demonstrating that reeler cells treated with Reelinenriched medium partially recovered the chain migratory ability (Fig. $4 \mathrm{H}$ ). Interestingly, the stable transfection with $\mathrm{pCrl}$ partially reinduced a chain-like migratory modality in reeler stem cells (Fig. 4I). Altogether these results indicate that Reelin is specifically involved in the mode, but not in the extent, of migration of murine postnatal neural stem cells.

\section{Reeler NSCS show impaired tropism towards gliomas}

The further step we took was the analysis of the in vivo behavior of reeler NSCs, specifically focusing on their ability to migrate through brain parenchyma towards a pathological stimulus represented by an experimentally induced glioma. To investigate the fate and the migrating capacity of NSCs derived from wild type vs. reeler mice, we stereotactically injected GL261 mouse glioma cells into the left nucleus caudatus of C57BL6N mice (day-7, Fig. 5, upper panel); seven days later we injected NSCs (either wild type or reeler) into the controlateral, right hemisphere (day 0, Fig. 5, upper panel). Both wild type and reeler cells had been previously infected with a lentiviral reporter construct expressing GFP, thus allowing for a precise evaluation of NSC localization throughout the brain. We then searched for migrated NSCs by flow cytometry and by histologic analysis at two time points, 7 and 14 days, after NSC injection. Fig. 5A shows that on day 7 only NSCs from wt mice started to migrate away from the
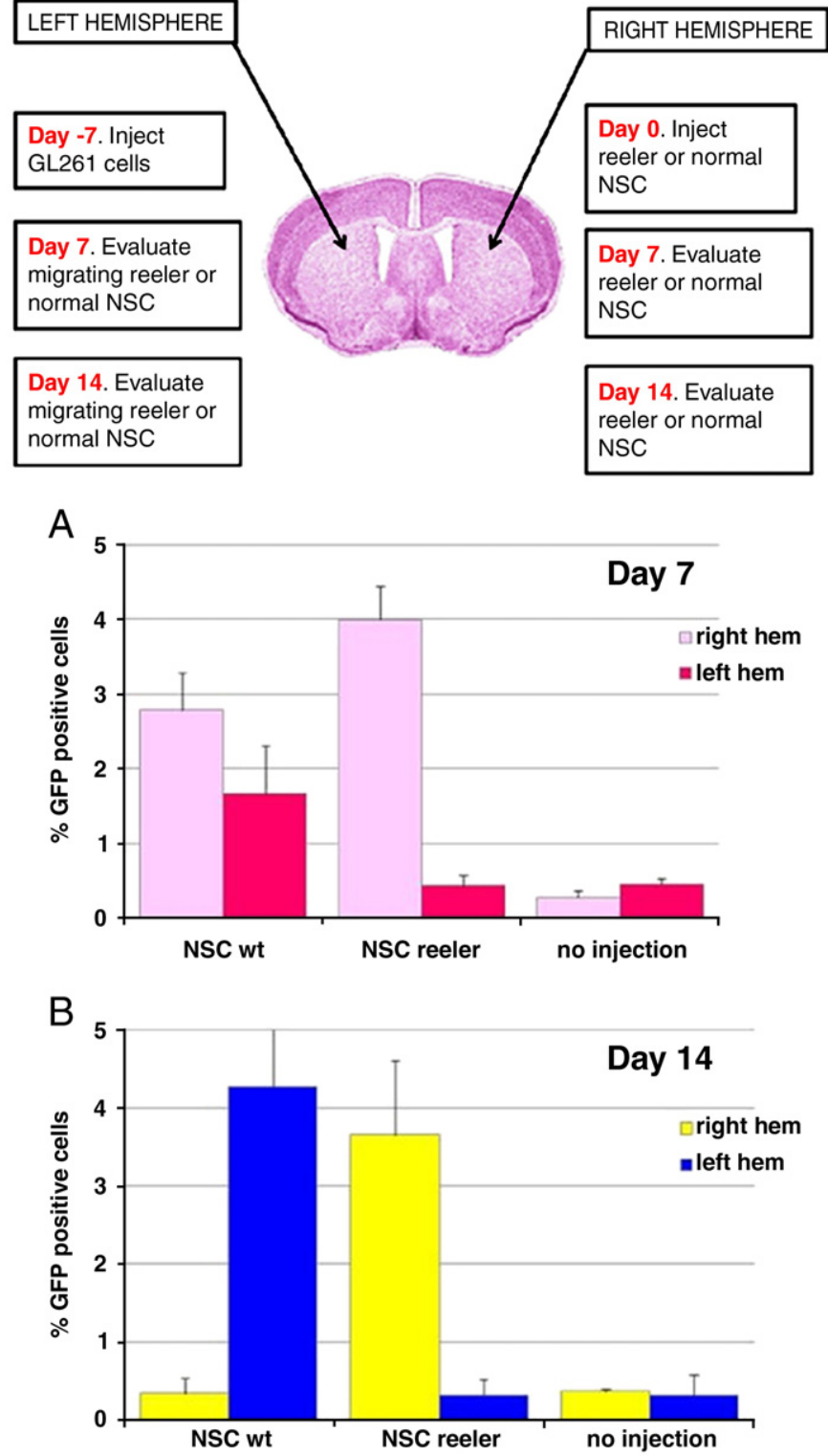

Fig. 5. Migratory potential of wild type or reeler NSCs towards GL261 gliomas. The upper part of the figure provides a schematic representation of the experimental design. The day of GL261 glioma cell injection into the left hemisphere is indicated as day "-7". Panels A-B. Flow cytometry analysis of GFP-NSCs after injection into mouse brain. NSCs were injected into the right brain hemisphere one week after implantation of GL261 glioma cells into the left hemisphere, and the migratory potential was investigated 7 (A) and 14 days (B) after NSC injection. The histograms show the percentage of GFP-positive cells detected in each type of hemisphere at two subsequent time points. Panel A: on day 7, a fraction of wt GFP-NSC was still detected in the right hemisphere, but a significant amount of GFP-positive cells was present in the left hemisphere, where tumor cells had been injected. Reeler GFP-NSCs were only detected in the right hemisphere. Panel B: on day 14, the fluorescence corresponding to wild type NSCs was detected almost exclusively in the left hemisphere; on the contrary, GFP fluorescence from reeler NSCs was confined to the right hemisphere where NSCs had been injected. ( $n=5$ for each experimental group).

injection site and to partially invade the tumor area in the contralateral hemisphere. On day 14 (Fig. 5B), the large majority of GFP-NSCs had migrated to the vicinity of the tumor (day 7: $2.8 \pm$ $0.34 \%$ right hemisphere, $1.7 \pm 0.7 \%$ left hemisphere, $P=0.02$; day 14 : $0.3 \pm 0.2 \%$ right hemisphere, $4.3 \pm 1.1 \%$ left hemisphere, $P=0.0001$ ). This significant difference was not observed when we injected GFPNSCs from reeler mice: in that case the majority of injected cells remained in the right hemisphere at both time points (day $7: 3.9 \pm$ $0.5 \%$ right hemisphere, $0.4 \pm 0.2 \%$ left hemisphere; day $14: 3.7 \pm 0.9 \%$ 


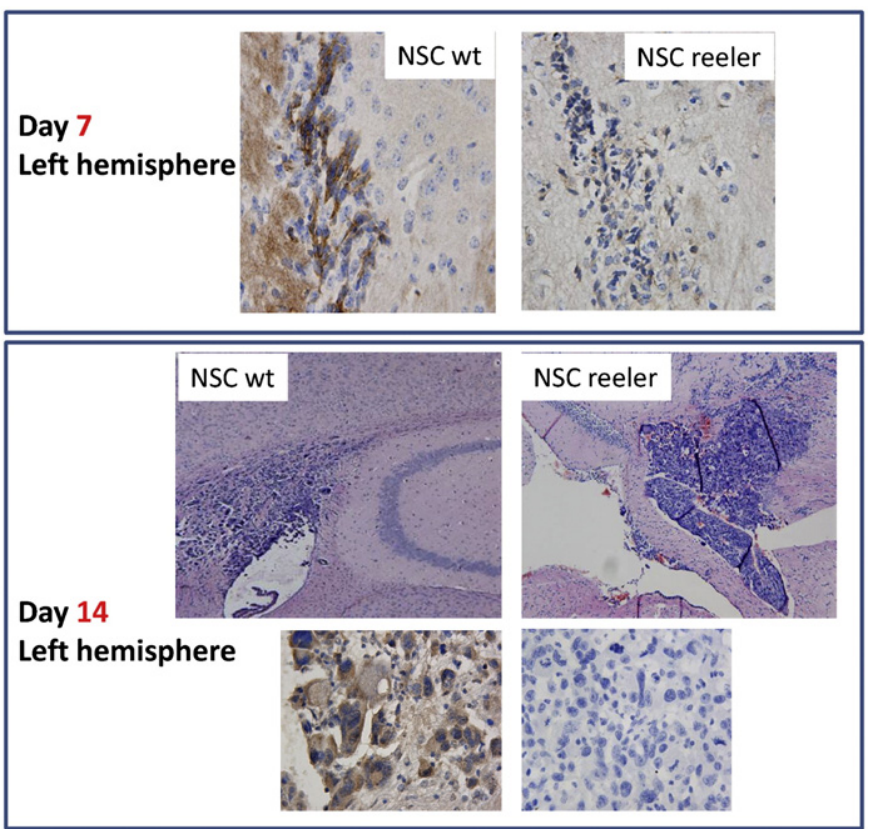

Fig. 6. Morphological analysis of migration of wild type or reeler NSCs in the presence of GL261 gliomas. Top panel. Left: immunohistochemical staining $(40 \times)$ with anti-GFP antibody of wild type (wt) GFP-positive NSCs inside the tumor mass. On day 7, a significant amount of GFP-positive cells was present in the left hemisphere, where tumor cells had been injected. Right: tumor area $(40 \times)$ stained by anti-GFP antibody 7 days after injection of reeler GFP + NSCs. No infiltrating GFP + cells are detectable in the tumor mass. Lower panel. Larger pictures show hematoxylin-eosin staining $(5 \times)$ of GL261 gliomas present in the left hemisphere 14 days after the controlateral injection of wild type NSCs (left) or reeler NSCs (right). GFP-positive, wild type NSCs were detected in the left hemisphere (smaller picture on the left, magn. 40x), while GFPpositive reeler NSCs were absent (smaller figure on the right, magn $40 \times$ ). $n=5$ for each experimental group.

right hemisphere, $0.3 \pm 0.2 \%$ left hemisphere). The histology confirmed these findings. On day 7 GL261 tumors in all mice investigated were small and localized in the vicinity of the injection site; a sizable number of wild type NSCs had migrated out of the injection point, attracted towards the left hemisphere where they infiltrated the tumor mass (Fig. 6, upper left panel). Reeler NSCs, on the contrary, remained in the right hemisphere in the vicinity of the injection site and no infiltrating GFP+ cells were detectable in the tumor mass. (Fig. 6, upper right panel). Later on, fourteen days after NSC implantation, a significant number of wild type NSCs had migrated along the corpus callosum, populating the tumor area (Fig. 6, lower left panels). Yet, reeler NSCs did not migrate away and remained around the injection track (Fig. 6, lower right panels). These findings support the hypothesis that Reelin production by NSCs is necessary to migrate towards established brain tumors.

\section{Discussion}

Reelin function in neuronal migration during cerebral development has been extensively investigated, establishing Reelin as a key factor regulating the correct formation of the developing neocortex (Gaiano, 2008). However, the documented persistence of Reelin expression in specific areas of the adult mammalian brain (Alcantara et al., 1998; Pesold et al., 1998; Ramos-Moreno et al., 2006) supports a role for this protein also in the adulthood. In the adult brain the ability of migration is retained by a very restricted category of cells, the neural stem cells and their immediate progeny, the neural precursors, often recruited by sites of brain injury, such as brain tumors. In this work we have shown that the absence of Reelin severely affects some key characteristics of postnatal mouse neural stem cells, among which the chain migration modality is probably the most significant in the possible frame of a role for Reelin as a regulator of NSC migration in the adult brain. What is most notable, in our opinion, is that reeler NSCs, totally lacking Reelin, are still able to migrate in vitro, to the same extent as wild type cells do; however reeler cells move in a sort of disorganized way, dispersing all around cells from the originating neurospheres, while wild type cells get together in very well distinguishable cell cords, called chains. In both wild type and reeler cases, the migrating cells show stem cell features, like nestin immunopositivity and the absence of immunoreactivity for $\beta$-III tubulin or GFAP, suggesting that the observed migration behavior is not due to different populations of cells engaged in the process in the two cases. Our data about the involvement of Reelin in chain migration of postnatal NSCs may appear in contrast with some previously published reports (Hack et al., 2002; Andrade et al., 2007) postulating for Reelin a role as a detachment factor. However, the experimental systems employed in those works were different from ours, as they both compared reeler and wild type SVZ explants. That experimental set up did not allow to clearly distinguish the stem cells from other cell types constituting the explants. On the contrary, our experiments were performed with isolated and characterized in vitro neurosphere-forming cells. Moreover, in one of those works an observation was made which is in total agreement with our hypothesis: in reeler mice, the rostral migratory stream was absent, while a massive accumulation of non-migrated NSCs was observed in the SVZ. This very well fits with our hypothesis that Reelin is needed for the chain migration mode commonly used by NSCs to move from the SVZ to the olfactory bulb, and employed by the same cells when recruited to a site of brain injury. Notably, Reelin rescue, by means either of endogenous supplementation or of stable transduction of reeler NSCs, restored chain migration ability, even if not completely. This is in agreement with our hypothesis that Reelin is deeply involved in NSC chain migration. In this view, Reelin should not be considered as a migration promoting factor, but rather as a modulator of the migratory process, assuring that it takes place in the correct, chain-like, way. The key importance of this finding is demonstrated by our in vivo data, showing that reeler NSCs challenged by a pathological stimulus, a brain tumor, are not able to reach it, as opposed to wild type NSCs. Of note, our in vivo experiments were performed in wild type mice. This suggests that Reelin exerts a cell-autonomous role in this specific function, where the protein produced in each neural stem cell is likely able to affect the migratory mode of the cell itself and of its immediate neighbors.

The mechanism through which Reelin modulates NSC migration in the adult brain has not been investigated and surely deserves specific studies. We showed that the genes encoding for two key mediators of Reelin extracellular function, the VLDL receptor and the intracellular adaptor Dab1, are expressed in both wild type and reeler NSCs; moreover, reeler NSCs retained the ability to respond to Reelin, as shown by rescue experiments. This might imply that, in adult neural stem cells, Reelin acts through similar mechanisms as in the developing brain.

It must be underlined that chain migration is not only an "emergency" response, induced by acute pathological insults in mammalian brain: rather, it is the physiological way through which NSCs migrate in adult rodent brains from the SVZ to the olfactory bulb via the rostral migratory stream (Lois and Alvarez-Buylla, 1994; Alvarez-Buylla and Garcia-Verdugo, 2002; Lledo et al., 2006; Wichterle et al., 1997). The ultimate fate of migrating NSCs is then to differentiate in order to re-populate specific target areas, also in the adult brain. Our data show an involvement of Reelin in this aspect of NSC biology too, as reeler NSCs appear to be less neurogenic than wild type ones, whereas their ability to differentiate towards astrocytes is intact. Reeler NSC defect in neuronal differentiation is at least partially rescued by exogenous Reelin, strongly supporting a direct involvement of Reelin in this process. This is in agreement with a previous report (Zhao et al., 2007), describing impaired neurogenesis, but not gliogenesis, in the adult reeler dentate gyrus, one of the brain regions 
with ongoing postnatal neurogenesis. Recently, apparently conflicting data have been published claiming that NSC differentiation into neurons or astrocytes is independent of Reelin (Kwon et al., 2009). In that work, the authors observe that the supplementation of $\mathrm{pCrl}-$ transfected 293T cell conditioned medium to wild type embryonic (E12.5) NSCs does not affect the differentiation into neurons or astrocytes; in addition, the differentiation of reeler embryonic NSCs, measured by Western blot of neuronal and glial markers, was not found to be different from that of analogous wild type cells. Although we do not have a definite explanation for these contrasting results, we hypothesize that they might be justified by the different developmental stages of NSCs employed in the experiments: postnatal cells in our case, embryonic cells in Kwon's work. The response to Reelin with respect to the differentiation potential of postnatal vs. embryonic stem cells might be different, as Reelin might exert diversified functions along time. In our work we also link, for the first time, Reelin expression to the ability of NSCs to proliferate and to form neurospheres: reeler neurospheres are reproducibly smaller and less abundant than their wild type counterparts. This might be mediated by multiple mechanisms, including not only the mere proliferation ability, but also the interaction and direct contact among cells. In fact, Reelin is involved in the modulation of cytoskeletal structure (Kawauchi and Hoshino, 2008), tightly linked to cell-cell interactions. Once again, the underlying mechanism awaits a further demonstration, as we cannot exclude that Reelin effects may be indirect: Notchmediated cell aggregation due to Reelin presence in wild type cells might act as an inducer of cell proliferation, as previously demonstrated to be the case for neural stem cells (Mori et al., 2006). This can be relevant due to recent evidence for a tight interaction of Reelin and Notch in regulating neuronal migration (Hashimoto-Torii et al., 2008).

The three biological effects of Reelin that we have described in NSCs might be independent, representing the multi-task activity of this protein, or tightly interconnected. In both cases, however, they affect three basic features of neural stem cells: self-renewal, differentiation and migration. These observations may shed new light on Reelin and its role as a modulator of NSC biology and could be relevant to explain the lifelong presence of Reelin in the adult brain. This is very important, specifically when considering neural stem cells as "anti-tumor bullets" targeting glioblastoma and possibly carrying therapeutic molecules to the tumor area. Our in vivo data, besides suggesting the importance of chain-migration for this function of NSCs, indicate Reelin as an indispensable signal needed by migrating NSC to correctly find their way to the tumor site.

\section{Experimental methods}

\section{Cell cultures}

The murine glioma cell line, GL261 adherent cells, was grown in DMEM (EuroClone, Wetherby, United Kingdom), 20\% fetal bovine serum (Life Technologies, CA), L-glutamine, and penicillin/ streptomycin.

\section{Animals and genotyping}

Heterozygous reeler (reelin $+/-$ ) mice were obtained from the Jackson Laboratory (B6C3Fe a/a-Relnrl/ + crossed with C57BL6/J). All mice were treated in accordance with the policy of the Italian Ministry of Health on the use of animals in research and all experiments were approved by the Ethical Committee of the University of Rome Tor Vergata and of the Istituto Neurologico Besta, Milano. Mouse littermates were obtained by heterozygous crossing, and genotyped by PCR of tail genomic DNA. The PCR primers used for genotyping were as follows:

\section{Up: 5'TAATCTGTCCTCACTCTGCC3'}

Down WT: 5'ACAGTTGACATACCTTAACC3'

Down RL: 5'TGCATTAATGTGCAGTGTTG3'.

\section{Isolation of neural progenitor cells}

Neural stem/progenitor cells were isolated from the brains of wild type or homozygous reeler mice at postnatal days 1 to 3 . Brains were isolated, deprived of the cerebellum and of the frontal part containing the $\mathrm{OB}$. Tissues were mechanically dissociated and the resulting cell suspensions were plated in the presence of $20 \mathrm{ng} / \mathrm{ml}$ human recombinant EGF (Peprotech) and $10 \mathrm{ng} / \mathrm{ml}$ human recombinant bFGF (Peprotech) in NS-A basal serum-free medium (Celbio) supplemented with $0.1 \times$ DMEM-F12 (Invitrogen), $2 \mathrm{mML}$-glutamine (Invitrogen), 1\% penicillin-streptomycin (Gibco), $0.5 \mathrm{mM}$ hepes (Sigma-Aldrich), $0.06 \%$ glucose, $12.5 \mu \mathrm{M}$ apotransferrine (SigmaAldrich), $43 \mu \mathrm{M}$ insulin (Sigma-Aldrich), $60 \mu \mathrm{M}$ putrescine (SigmaAldrich), $0.03 \mu \mathrm{M}$ selenium (Sigma-Aldrich), and $0.02 \mu \mathrm{M}$ progesterone (Sigma-Aldrich). In these conditions, cells rapidly grow to form neurospheres (Gritti et al., 1996). After 7 days, cultures were collected, mechanically dissociated and re-plated in the same conditions. Bulk cultures were generated by passaging the cells every $5-7$ days (1:5) in the same growth medium. Cell number and viability were determined at every passage by trypan blue exclusion. All experiments were performed employing cells from 20th to the 30th passage.

\section{Reverse transcription-PCR}

Total RNA was isolated using Trizol ${ }^{\circledR}$ (Invitrogen), and cDNA was generated with M-MLV Reverse Transcriptase (Promega). Equal amounts of first strand cDNA were used as templates for PCR reactions $\left(1 \times 3^{\prime}\right.$ a $94{ }^{\circ} \mathrm{C} ; 35 \times 30^{\prime \prime} 94^{\circ} \mathrm{C}, 30^{\prime \prime} 56^{\circ} \mathrm{C}, 1^{\prime} 72^{\circ} \mathrm{C} ; 1 \times 10^{\prime}$ a $72{ }^{\circ} \mathrm{C}$ ). The RT-PCR primer sequences were as follows:

\section{Dab1 up 5'-TTTAACCATCTCCTTTGGAGGA-3'}

Dab1 down 5'-ACGAATAGCCATTACTTACAGG-3' producing an amplified band of $370 \mathrm{bp}$

VLDLR up 5'-GGCTATCAAATGGATCTTGCT-3'

VLDLR down 5'-TTGCAGTACTTTGACAGTCTC-3' producing an amplified band of $990 \mathrm{bp}$.

\section{Neurosphere formation and growth assays}

Secondary neurospheres were harvested, and mechanically dissociated to obtain a single neural stem cell suspension. A defined number of cells was plated and neurosphere formation was monitored. In detail, $6 \times 10^{4}$ cells were plated onto 6 -well plates (Iwaki), and grown for 10 days, after which ten digital pictures were taken per well. The diameter of neurospheres was measured by Photoshop software. Neurospheres located at the edges of the pictures, or those smaller than $200 \mu \mathrm{m}$ in diameter were excluded. A time course of cell growth within neurospheres was performed by collecting neurospheres at 5, 9 and 11 days after plating, mechanically dissociating them, and counting by trypan blue. In addition, increasing numbers (250, 500, 1000 and 2000 ) of cells were plated onto 24-well plates (Iwaki), and the final cell number was counted at day 11 from plating. Neurospheres smaller than $200 \mu \mathrm{m}$ in diameter were excluded from measurements.

\section{Quantification and assay of NSC chain migration}

Seven days after plating, the neurospheres were harvested and plated onto 6-well plates (Iwaki) precoated with fibronectin $(2 \mu \mathrm{g} / \mathrm{ml}$ in PBS, $24 \mathrm{~h} 4{ }^{\circ} \mathrm{C}$ ), or polyornithine/fibronectin ( $15 \mu \mathrm{g} / \mathrm{ml}$ poly-L-ornithine in PBS, $12 \mathrm{~h} 37^{\circ} \mathrm{C}$, followed by an o.n. wash in PBS, then $1 \mu \mathrm{g} / \mathrm{ml}$ fibronectin in PBS, $\left.12 \mathrm{~h} 37^{\circ} \mathrm{C}\right)$, or gelatin $\left(0.5 \%\right.$ in water, o.n. $\left.37^{\circ} \mathrm{C}\right)$, or polylysine $(0.001 \%$ in borate buffer $0.1 \mathrm{M} \mathrm{pH} 8.4,24 \mathrm{~h} \mathrm{RT})$. The culture medium was the same as described above, but in some cases 0.1 volume of Reelin-containing conditioned medium was included at plating, and added again after $24 \mathrm{~h}$. The spheres were monitored on a Nikon inverted 
microscope ( $4 \times$ and $10 \times$ ), and phase-contrast images were taken 24,48 , 72 and $96 \mathrm{~h}$ after plating. Digital images of neurospheres from three different experiments were recorded and analyzed. When needed, cells were permeabilized with $0.2 \%$ Triton X-100 and subsequently fixed with $4 \%$ paraformaldehyde for immunofluorescence analysis.

In vitro cell migration assay

In vitro migration of NSCs toward glioma conditioned medium was examined using Boyden chamber assays. $24 \mathrm{~mm}$ diameter Transwell ${ }^{\circledR}$ (Corning, Costar) were used, where each well of the plates was separated into two chambers by an insert polycarbonate membrane of $8 \mu \mathrm{m}$ pores treated with $2.5 \mu \mathrm{g} / \mathrm{ml}$ fibronectin for $24 \mathrm{~h}$, in order to favor cell adhesion. Growing neurospheres were dissociated, counted, and $4 \times 10^{5}$ cells in $3 \mathrm{ml}$ were seeded into the upper chambers of the Transwell, while the lower chambers were filled with U87MG conditioned medium. Cell migration in response to serum-free DMEM was used as the basal migration rate. After $22 \mathrm{~h}$ of incubation at $37^{\circ} \mathrm{C}$, migrating cells on the bottom of the insert membrane were fixed by methanol/acetone $\left(3: 7,5^{\prime}-20^{\circ} \mathrm{C}\right)$, and nonmigrating cells on the upper side of the membrane were scratched away by a scraper. The membrane was treated with DAPI $(1 \mu \mathrm{g} / \mathrm{ml}, 5 \mathrm{RT})$ and visualized by a Nikon inverted microscope (Nikon eclipse E600, 40× magnification). 6 fields were counted per membrane, defining as migrated those cells located on the lower side of the membrane. Values were expressed as the mean \pm SD in percentage control.

\section{Differentiation assay}

4-well culture slides (BD Falcon) were treated $1 \mathrm{~h}$ at RT with Low Factor Matrigel (BD Biosciences, diluted 1:50 in differentiation medium, see below), in order to abolish possible proliferation stimulating action. Actively growing neurospheres (3-4 days from plating) were collected, mechanically dissociated and live cells were counted by trypan blue exclusion. Cell suspensions containing more than $10 \%$ of dead cells were not used for the assay. $1 \times 10^{5}$ cells were plated in each well in differentiation medium (NS-A medium (Celbio) supplemented with $0.1 \times$ DMEM-F12 (Invitrogen), 2 mM L-glutamine (Invitrogen), $100 \mu \mathrm{g} / \mathrm{ml}$ penicillin and streptomycin (Invitrogen), $1.5 \%$ fetal bovine serum (FBS, Lonza), $0.5 \mathrm{mM}$ hepes (Gibco), $0.06 \%$ glucose, $12.5 \mu \mathrm{M}$ apotransferrin (Sigma-Aldrich), $43 \mu \mathrm{M}$ insulin (Sigma-Aldrich), $60 \mu \mathrm{M}$ putrescin (Sigma-Aldrich), $0.03 \mu \mathrm{M}$ selenium (Sigma-Aldrich), $0.02 \mu \mathrm{M}$ progesterone (Sigma-Aldrich)). Some experiments were performed by adding 0.1 volume of Reelincontaining conditioned medium at plating, and then re-adding it after $24 \mathrm{~h}$. After four days cells were fixed by methanol/acetone (3:7, $5^{\prime}-20^{\circ} \mathrm{C}$ ), stained and analyzed by immunofluorescence.

\section{Immunocytochemistry}

Fixed cells were rehydrated in PBS $10^{\prime}$ at RT. Blocking was performed in 3\% BSA (Sigma) in PBS for $1 \mathrm{~h}$ at RT, followed by incubation with mouse anti-nestin (1:100, Chemicon), mouse antiTuJ (1:500, Covance), rabbit anti-GFAP (1:300, DakoCytomation), mouse anti-MAP-2ab (1:500, Immunological Sciences), mouse antiNF-H (1:500, Immunological Sciences) and mouse anti-NFM, (1:500, Immunological Sciences). All primary antibodies were diluted in PBS$0.1 \%$ BSA and incubated $1 \mathrm{~h}$ at RT. Cells were washed three times in PBS (5' at RT), exposed to 1:400 goat anti-rabbit IGG Alexa Fluor ${ }^{\circledR}$ (Molecular Probes) or 1:600 goat anti-mouse IGG Cy3 (Chemicon) secondary antibodies for $1 \mathrm{~h}$ at RT. After incubation, cells were washed three times in PBS ( $5^{\prime}$ at RT) and nuclei were labelled with $1 \mu \mathrm{g} / \mathrm{ml}$ DAPI in PBS. 1000 nuclei were counted for each well. Negative controls omitting the primary antibodies were carried out in all experiments. Cells were visualized by a Nikon inverted microscope (Nikon eclipse E600, 40× magnification).

\section{Preparation of Reelin conditioned media and Western blot}

Reelin- and control-conditioned media were collected from HeLa cells stably transfected with Reelin pCRL vector (D'Arcangelo et al., 1997) and a control empty pcDNA3.1 vector (Invitrogen), respectively. Conditioned medium of Reelin-synthesizing HeLa cells and the negative control medium were collected and centrifuged at $4000 \times \mathrm{g}$ for $5 \mathrm{~min}$ to remove dead cells. Before use, Reelin-enriched supernatants were concentrated about 100-fold with Centricon 100 columns (Amicon, Millipore), and stored at $-70{ }^{\circ} \mathrm{C}$. Reelin level was confirmed by Western blotting using anti-Reelin clone E142 (Chemicon), recognizing the C-terminal region of Reelin, that detected the three characteristic bands of Reelin $(400 \mathrm{kDa}, 300 \mathrm{kDa}$, and $180 \mathrm{kDa})$. In detail, after denaturation $\left(95^{\circ} \mathrm{C} 5^{\prime}\right)$ by addition of 2 vol sample buffer, $10 \mu \mathrm{l}$ of supernatant was loaded per well, and proteins were separated by SDS/PAGE (5\%-8\%) and then blotted onto polyvinylidene difluride (PVDF) membranes (Hybond-P, Amersham Pharmacia Biotech) for $150 \mathrm{~min}$ at $250 \mathrm{~mA}$. Membranes were blocked with $5 \%$ $(\mathrm{w} / \mathrm{v})$ nonfat milk (BioRad) in Tris-buffered saline-PBS (TBPS) at room temperature for $1 \mathrm{~h}$, and finally incubated with E142 (Chemicon) primary antibody (1:1000), in blocking solution at $4{ }^{\circ} \mathrm{C}$ overnight. After washing, membranes were incubated with a horseradish peroxidase-conjugated secondary antibody (Chemicon) at a concentration of 1:2000. The immunoreaction was visualized by enhanced chemiluminescence (ECL) (Amersham Bioscience).

\section{Transfection of NSCS}

Actively growing neurospheres (3-4 days from plating) were collected, mechanically dissociated and live cells were counted by trypan blue exclusion. $5 \times 10^{5}$ cells were then transfected with $2 \mu \mathrm{g}$ of DNA/well using lipofectamine according to the manufacturer's instructions (Invitrogen). Neurospheres started to form again after $12 \mathrm{~h}$. At $48 \mathrm{~h}$ from transfection, $0.15 \mathrm{mg} / \mathrm{ml} \mathrm{G} 418$ (Invitrogen) was added to the medium for selecting stable transfectants, that were definitely established in about 5 weeks.

\section{Lentiviral transduction of NSCS}

For transduction, NSCs were mechanically dissociated by pipetting, plated in 6 -well plates at the density of $3 \times 10^{5} /$ well and infected with a lentiviral preparation containing $50 \mathrm{ng}$ of p24 in the presence of polybrene ( $6 \mu \mathrm{g} / \mathrm{ml}$ of medium). Generation of the lentiviral vector expressing the green fluorescent protein (GFP) was reported previously (Pellegatta et al., 2006). Before NSC injection, efficiency of lentiviral transduction was assessed by flow cytometry by evaluating the percentage of GFP-positive cells: $50 \%$ of NSC and $70 \%$ of NSC reeler were GFP-positive (data not shown).

\section{In vivo distribution of transduced NSCS}

To test the migratory ability of NSCs from wild type and reeler mice, 24 female C57BL6N mice (5-6 weeks old; Charles River, Lecco, Italy) were stereotactically injected into the right brain hemisphere with $4 \times 10^{5}$ either wild type (12 mice) or reeler (12 mice) GFP-NSCs. The NSC injection was performed one week after the injection of $5 \times 10^{4}$ GL261 mouse glioma cells or PBS into the nucleus caudatum ( $0.7 \mathrm{~mm}$ posterior, $3 \mathrm{~mm}$ right or left with respect to the bregma, and $3.5 \mathrm{~mm}$ deep).

To identify GFP-positive cells, flow cytometry was performed on brain homogenates of each hemisphere on day 7 (10 mice) and 14 (10 mice) after NSC injection. After brain excision, the two hemispheres were carefully separated and dissected by a scalpel to produce a single cell suspension. Large particles were removed by three consecutive centrifugations $(400 \times \mathrm{g}, 5 \mathrm{~min})$, and the final pellet passed through filters (70-50 $\mu$ m pores). Homogenized samples were diluted 20 -fold 
before acquisition by flow cytometry (minimum acquisition/hemisphere: $1 \times 10^{6}$ events). The basal level of autofluorescence was evaluated by measuring cell suspensions obtained from untrasplanted wild type mice as negative controls.

\section{Histology and immunohistochemistry}

Brains were removed, post-fixed in formaldehyde for $2-4 \mathrm{~h}$, washed in PBS, and embedded in paraffin. Hematoxylin and eosin (H\&E) staining was used to identify the tumor formation.

For immunohistochemical staining, sections underwent deparaffination, and were then rehydrated, washed in PBS, and exposed for $1 \mathrm{~h}$ to $10 \%$ goat serum and $0.5 \%$ BSA in PBS. Cells were then incubated at $4{ }^{\circ} \mathrm{C}$ overnight with primary antibody (rabbit polyclonal anti-green fluorescent protein (GFP), Santa Cruz Biotechnology, USA) (1:100) in the same buffer. After PBS washes, sections were incubated at RT with a biotinylated anti-rabbit secondary antibody (Vector laboratories, UK) (1:200) in PBS, and subsequently with streptavidin-HRP (1:300) (Dako, USA). DAB substrate was used to visualize immunoreactivity. One mouse each per experimental group was analyzed by this method.

\section{Statistical analysis}

Statistical analysis was performed by using the paired Student's $t$ test. For migratory analysis, a test for repeated measures (ANOVA) with Bonferroni correction for multiple comparisons was used. A $P$ value of $<0.05$ was considered significant.

\section{Acknowledgments}

This study was funded in part by grants from the Italian Ministry of Instruction, University and Scientific Research to SAC and MGF (PRIN 20077YZTL8_002), and from the "National Program on Stem Cells", and Italy-USA Collaborative Programme, Ministry of Health, to MGF and GF. SM was a recipient of a PhD fellowship in Advanced Technologies in Biomedicine, University of Rome "Tor Vergata". We thank Patrizia Tunici for initial help with migration experiments in glioma-bearing mice.

\section{References}

Aboody, K.S., Brown, A., Rainov, N.G., Bower, K.A., Liu, S., Yang, W., Small, J.E., Herrlinger U., Ourednik, V., Black, P.M., Breakfield, X.O., Snyder, E.Y., 2000. Neural stem cells display extensive tropism for pathology in adult brain: evidence from intracranial gliomas. Proc. Natl. Acad. Sci. USA 97, 12846-12851.

Aboody, K.S., Najbauer, J., Danks, M.-K., 2008. Stem and progenitor cell-mediated tumor selective gene therapy. Gene Ther. 15, 739-752.

Abraham, H., Meyer, G., 2003. Reelin-expressing neurons in the postnatal and adult human hippocampal formation. Hippocampus 13, 715-727.

Alcantara, S., Riuz, M., D'Arcangelo, G., Ezan, F., de Lecea, L., Curran, T., Sotelo, C., Soriano, E., 1998. Regional and cellular patterns of reelin mRNA expression in the forebrain of the developing and adult mouse. J. Neurosci. 18, 7779-7799.

Alvarez-Buylla, A., Garcia-Verdugo, J.M., 2002. Neurogenesis in adult subventricular zone. J. Neurosci. 22, 629-634.

Andrade, N., Komnenovic, V., Blake, S.M., Jossin, Y., Howell, B., Goffinet, A., Schneider, W.J. Nimpf, J., 2007. ApoER2/VLDL receptor and Dab1 in the rostral migratory stream function in postnatal neuronal migration independently of Reelin. Proc. Natl. Acad. Sci. USA 104 (20), 8508-8513.

Benedetti, S., Pirola, B., Pollo, B., Magrassi, L., Buzzone, M.G., Rigamonti, D., Galli, R. Selleri, S., Di Meco, F., De Fraja, C., Vescovi, A., Cattaneo, E., Finocchiaro, G., 2000. Gene therapy of experimental brain tumors using neural progenitor cells. Nat. Med. $6,447-450$

D'Arcangelo, G., Homayouni, R., Keshvara, L., Rice, D.S., Sheldon, M., Curran, T., 1999 Reelin is a ligand for lipoprotein receptors. Neuron 24, 481-489.

D'Arcangelo, G., Miao, G.G., Chen, S.C., Soares, H.D., Morgan, J.I., Curran, T., 1995. A protein related to extracellular matrix proteins deleted in the mouse mutant reeler. Nature 374, 719-723.

D'Arcangelo, G., Nakajima, K., Miyata, T., Ogawa, M., Mikoshiba, K., Curran, T., 1997. Reelin is a secreted glycoprotein recognized by the CR-50 monoclonal antibody. J. Neurosci. 17 (1), 23-31.

Doetsch, F., Alvarez-Buylla, A., 1996. Network of tangential pathways for neurona migration in adult mammalian brain. Proc. Natl. Acad. Sci. USA 93, 14895-14900.
Doetsch, F., Caille, I., Lim, D.A., Garcia-Verdugo, J.M., Alvarez-Buylla, A., 1999. Subventricular zone astrocytes are neural stem cells in the adult mammalian brain. Cell 97, 703-716.

Doetsch, F., Petreanu, L., Caille, I., Garcia-Verdugo, J.M., Alvarez-Buylla, A., 2002. EGF converts transit-amplifying neurogenic precursors in the adult brain into multipotent stem cells. Neuron 36, 1021-1034.

Eriksson, P.S., Perfilieva, E., Bjork-Eriksson, T., Alborn, A.M., Nordborg, C., Peterson, D.A., Gage, F.H., 1998. Neurogenesis in the adult human hippocampus. Nat. Med. 4, 1313-1317.

Flax, J.D., Aurora, S., Yang, C., Simonin, C., Wills, A.M., Billinghurst, L.L., Jendoubi, M., Sidman, R.L., Wolfe, J.H., Kim, S.U., Snyder, E.Y., 1998. Engraftable human neural stem cells respond to developmental cues, replace neurons, and express foreign genes. Nat. Biotechnol. 16 (11), 1033-1039.

Gage, F.H., 2000. Mammalian neural stem cells. Science 287, 1433-1438.

Gaiano, N., 2008. Strange bedfellows: Reelin and Notch signaling interact to regulate cell migration in the developing neocortex. Neuron 60, 189-191.

Gritti, A., Parati, E.A., Cova, L., Frolichsthal, P., Galli, R., Wanke, E., Faravelli, L., Morassutti, D.J., Roisen, F., Nickel, D.D., Vescovi, A.L., 1996. Multipotential stem cells from the adult mouse brain proliferate and self-renew in response to basic fibroblast growth factor. J. Neurosci. 16, 1091-1100.

Hack, I., Bancila, M., Loulier, K., Carroll, P., Cremer, H., 2002. Reelin is a detachment signal in tangential chain-migration during postnatal neurogenesis. Nat. Neurosci. 5, 939-945.

Hashimoto-Torii, K., Torii, M., Sarkisian, M.R., Bartley, C.M., Shen, J., Radtke, F., Gridley, T., Sestan, N., Rakic, P., 2008. Interaction between Reelin and Notch signaling regulates neuronal migration in the cerebral cortex. Neuron 60 (2), 273-284.

Johansson, C.B., Momma, S., Clarke, D.L., Risling, M., Lendahl, U., Frisen, J., 1999. Identification of a neural stem cell in the adult mammalian central nervous system. Cell 96, 25-34.

Kawauchi, T., Hoshino, M., 2008. Molecular pathways regulating cytoskeletal organization and morphological changes in migrating neurons. Dev. Neurosci. 30 $(1-3), 36-46$

Kim, H.M., Qu, T., Kriho, V., Lacor, P., Smalheiser, N., Pappas, G.D., Guidotti, A., Costa, E., Sugaya, K., 2002. Reelin function in neural stem cell biology. Proc. Natl. Acad. Sci. USA 99, 4020-4025.

Kwon, I.S., Cho, S.K., Kim, M.J., Tsai, M.J., Mitsuda, N., Suh-Kim, H., Lee, Y.D., 2009. Expression of Disabled 1 suppresses astroglial differentiation in neural stem cells. Mol. Cell. Neurosci. 40 (1), 50-61.

Lledo, P.M., Alonso, M., Grubb, M.S., 2006. Adult neurogenesis and functional plasticity in neuronal circuits. Nat. Rev., Neurosci. 7, 179-193.

Lois, C., Alvarez-Buylla, A., 1994. Long-distance neuronal migration in the adult mammalian brain. Science 264, 1145-1148.

Luskin, M.B., 1993. Restricted proliferation and migration of postnatally generated neurons derived from the forebrain subventricular zone. Neuron 11, 635-647.

Martinez-Cerdeno, V., Galazo, C., Cavada, M.J., Clasca, F., 2002. Reelin immunoreactivity in the adult primate brain: intracellular localization in projecting and local circuit neurons of the cerebral cortex, hippocampus and subcortical regions. Cereb. Cortex $12,1298-1311$

Mori, H., Ninomiya, K., Kino-oka, M., Shofuda, T., Islam, M.O., Yamasaki, M., Okano, H., Taya, M., Kanemura, Y., 2006. Effect of neurosphere size on the growth rate of human neural stem/progenitor cells. J. Neurosci. Res. 84 (8), 1682-1691.

Morshead, C.M., Reynolds, B.A., Craig, C.G., McBurney, M.W., Staines, W.A., Morassutti, D., Weiss, S., van der Kooy, D., 1994. Neural stem cells in the adult mammalian forebrain: a relatively quiescent subpopulation of subependymal cells. Neuron 13 , 1071-1082.

Park, K.I., Teng, Y.D., Snyder, E.Y., 2002a. Nat. Biotechnol. 20, 1111-1117.

Park, K.Y., Ourednik, J., Ourednik, V., Taylor, R.M., Aboody, K.S., Auguste, K.I., Lachyankar, M.B., Redmond, D.E., Snyder, E.Y., 2002b. Global gene and cell replacement strategies via stem cells. Gene Ther. 9, 613-624.

Pellegatta, S., Tunici, P., Poliani, P.L., Dolcetta, D., Cajola, L., Colombelli, C., Ciusani, E., Di Donato, S., Finocchiaro, G., 2006. The therapeutic potential of neural stem/ progenitor cells in murine globoid cell leukodystrophy is conditioned by macrophage/microglia activation. Neurobiol. Dis. 21 (2), 314-323.

Pesold, C. Impagnatiello, F. Pisu, M.G. Uzunov, D.P. Costa, E., Guidotti, A. Caruncho, H.J. 1998. Reelin is preferentially expressed in neurons synthesizing $\gamma$-aminobutyric acid in cortex and hippocampus of adult rats. Proc. Natl. Acad. Sci. USA 95, 3221-3226.

Ramos-Moreno, T., Galazo, M.J., Porrero, C., Martinez-Cerdeno, V., Clasca, F., 2006. Extracellular matrix molecules and synaptic plasticity: immunomapping of intracellular and secreted Reelin in the adult rat brain. Eur. J. Neurosci. 23, 401-422.

Reynolds, B.A., Weiss, S., 1992. Generation of neurons and astrocytes from isolated cells of the adult mammalian central nervous system. Science 255, 1707-1710.

Snyder, E.Y., Yoon, C., Flax, J.D., Macklis, J.D., 1997. Multipotent neural precursors can differentiate toward replacement of neurons undergoing targeted apoptotic degeneration in adult mouse neocortex. Proc. Natl. Acad. Sci. USA 94, 11663-11668.

Taupin, P., Gage, F.H., 2002. Adult neurogenesis and neural stem cells of the central nervous sytem in mammals. J. Neurosci. Res. 69, 745-749.

Wichterle, H., Garcia-Verdugo, J.M., Alvarez-Buylla, A., 1997. Direct evidence for homotypic, glia-independent neuronal migration. Neuron 18, 779-791.

Won, S.J., Kim, S.H., Xie, L., Wang, Y., Mao, X.O., Jin, K., Greenberg, D.A., 2006. Reelindeficient mice show impaired neurogenesis and increased stroke size. Exp. Neurol. 198 (1), 250-259.

Zhao, S., Chai, X., Frotscher, M., 2007. Balance between neurogenesis and gliogenesis in the adult hippocampus: role for reelin. Dev. Neurosci. 29 (1-2), 84-90.

Zhao, C., Wei, D., Gage, F.H., 2008. Mechanisms and functional implications of adult neurogenesis. Cell 132, 645-660. 